\title{
Migration, sexual behavior and HIV diffusion in Kenya
}

Martin Brockerhoff

Population Council

Ann E. Biddlecom

Population Council

Follow this and additional works at: https://knowledgecommons.popcouncil.org/departments_sbsr-pgy

Part of the Demography, Population, and Ecology Commons, Family, Life Course, and Society Commons, International Public Health Commons, and the Migration Studies Commons How does access to this work benefit you? Let us know!

\section{Recommended Citation}

Brockerhoff, Martin and Ann E. Biddlecom. 1998. "Migration, sexual behavior and HIV diffusion in Kenya," Policy Research Division Working Paper no. 111. New York: Population Council. 


\section{Migration, Sexual Behavior, and HIV D iffusion in Kenya}

$M$ artin B rockerhoff Ann Biddlecom

1998 No. 111 


\title{
Migration, Sexual Behavior, and HIV Diffusion in Kenya
}

\author{
Martin Brockerhoff \\ Ann Biddlecom
}

Martin Brockerhoff is Associate and Ann Biddlecom is Research Associate, Policy Research Division, Population Council. 


\begin{abstract}
The association of migration with the spread of AIDS in sub-Saharan Africa is well documented, yet the social and behavioral mechanisms underlying this relationship remain poorly understood. Using data from the 1993 Kenya Demographic and Health Survey, this paper examines whether migrants are more likely than nonmigrants to have multiple recent sexual partners and not to use condoms with those partners. Results indicate that migration is a critical factor in high-risk sexual behavior and that its importance varies by gender and by the direction of movement. Independent of marital and cohabitation status, social milieu, awareness of AIDS, and other crucial influences on sexual behavior, male migrants between urban areas, and female migrants within rural areas, are much more likely than nonmigrant counterparts to engage in sexual practices conducive to HIV infection. In rural areas, migrants from urban places are more likely than nonmigrants to practice high-risk sex. Given the predominance of men in urban migration and the large volume of circulatory movement between urban and rural areas, these results have serious implications for HIV transmission throughout Kenya.
\end{abstract}

This material may not be reproduced in any form without written permission from the authors. 
Geographic mobility is widely recognized as one of the main facilitating conditions of HIV transmission in sub-Saharan Africa (Fontanet and Piot 1994; Hunt 1989). Numerous studies have established a clear link between elevated HIV seroprevalence and short duration of residence in a locality (Allen et al. 1991; Barongo et al. 1992; Nunn et al. 1995), settlement or travel along major transportation routes (Carswell, Lloyd, and Howells 1989; Serwadda et al. 1992 ), immigrant status (Piot et al. 1987), and international travel to the region (Hawkes et al. 1994). Massive migration of young, unmarried adults from presumably "conservative" rural environments to more sexually permissive African cities in recent years is regarded as partly responsible for the much higher seroprevalence levels observed in urban than in rural areas (United Nations 1994:8).

Although the association of migration with the spread of AIDS in East, Central, and Southern Africa (the "AIDS Belt") is well documented, the social and behavioral mechanisms that may render migrants more vulnerable to HIV infection in this area remain poorly understood. Aside from migrants who are transport or commercial sex workers, there is scant evidence that migrants have distinct personal characteristics and sexual behaviors, such as high numbers of sexual partners or low condom use, that are conducive to contracting HIV. Since migrants are a large and heterogeneous group, it is crucial to understand not only how these behavioral aspects of infection vary between migrants and nonmigrants, but also how they differ among migrants: men versus women, in urban versus rural environments, and according to migrants' area of origin or socialization. Given that African cities generally continue to experience the world's highest rates of population growth (United Nations 1995) - with in-migration of young adults a major component of such growth (Becker, Hamer, and Morrison 1994) - this lack of information on migration-AIDS relationships is an obstacle to effective policies and 
programs to contain infection rates in urban areas. More important, the historical circular pattern of population movement in much of Africa (Adepoju 1984) suggests that improved understanding of the linkages between migration and HIV risk factors is also critical for controlling further spread of AIDS into rural areas, where most Africans reside.

The present study uses national data collected by the Demographic and Health Surveys (DHS) in Kenya in 1993 to test a critical hypothesis implied by much of the literature on migration and AIDS: that male and female migrants, in urban and rural settings, are more likely than nonmigrants to engage in sexual practices that elevate their risk of acquiring $\mathrm{HIV}$, and consequently AIDS (Caldwell, Anarfi, and Caldwell 1997; Chirwa 1997; Lurie et al. 1997). High-risk sexual behavior is defined by the number of recent heterosexual partners - the strongest individual determinant of infection (Dare and Cleland 1994) — and by nonuse of condoms with these partners. Of particular interest is whether migrants' previous exposure to urban environments increases their likelihood of high-risk behavior in rural areas, for example through socialization to less restrictive sexual norms or acquisition of enabling characteristics (for instance, wealth) in cities.

Kenya represents an ideal country for such a study given its rapidly growing number of HIV-infected persons, estimated at nearly 20 percent of a "low-risk" urban population (pregnant women) and 85.5 percent of a "highrisk" urban population (female prostitutes) (US Bureau of the Census 1995). The spread of AIDS in Kenya since the late 1970s has been concurrent with phenomenal urban growth: a tripling of the urban population between 1980 and 1995, and annual growth rates of about 6 percent in Nairobi, the capital city (United Nations 1995). Much of this growth is attributable to changing 
patterns of rural-urban migration since independence in 1963, specifically to more permanent settlement of males in cities and increased long-term circulation of females between areas of family settlement and economic opportunity (Thadani 1982). For example, almost half (46 percent) of reproductive-age women residing in cities of Kenya in 1989 had in-migrated from villages and towns during the previous ten years alone (Brockerhoff 1995). Nonetheless, frequent movement between cities or towns and the "home" village remains the norm for many urban migrants in Kenya (Gould 1988). High rates of HIV transmission, urban growth, and migration have been experienced in several other East and Southern African countries in recent years as well (National Research Council 1993). Therefore, while our analysis is based on data from one country, we believe that our findings have implications for other African countries where HIV seroprevalence levels are high.

\section{BACKGROUND}

For reasons discussed below, migrants in African countries with a relatively high prevalence of HIV/AIDS can be expected to have substantially higher HIV risks than nonmigrants as a result of different patterns of heterosexual behavior. It follows that high levels of population mobility, coupled with high infectivity levels among migrants, hasten the spread of AIDS. Riskier sexual behaviors among migrant groups have been attributed to three factors: 1) predisposing individual characteristics; 2) changes in individual attributes due to migration, notably separation from a spouse or partner; and 3) exposure to a new social environment, featuring different sexual norms, opportunities, and constraints that result in behavioral modification (see Figure 1). These three perspectives essentially derive from the concepts of migrant 
selectivity, life disruption, and urban adaptation, commonly used in studies of the fertility consequences of migration (Findley 1982; Goldstein and Goldstein 1982). They are also closely related to the Health Belief Model (HBM), a model used often in studies of health and contraceptive behavior (Janz and Becker 1984). In brief, the HBM assumes that an individual's characteristics, prior experiences, and current surroundings shape his or her perceptions concerning the risks and severity of behavioral outcomes - such as contracting the AIDS virus through sexual conduct - and thereby influence behavior.

Figure 1 Conceptual model of the influence of migration on sexual behavior

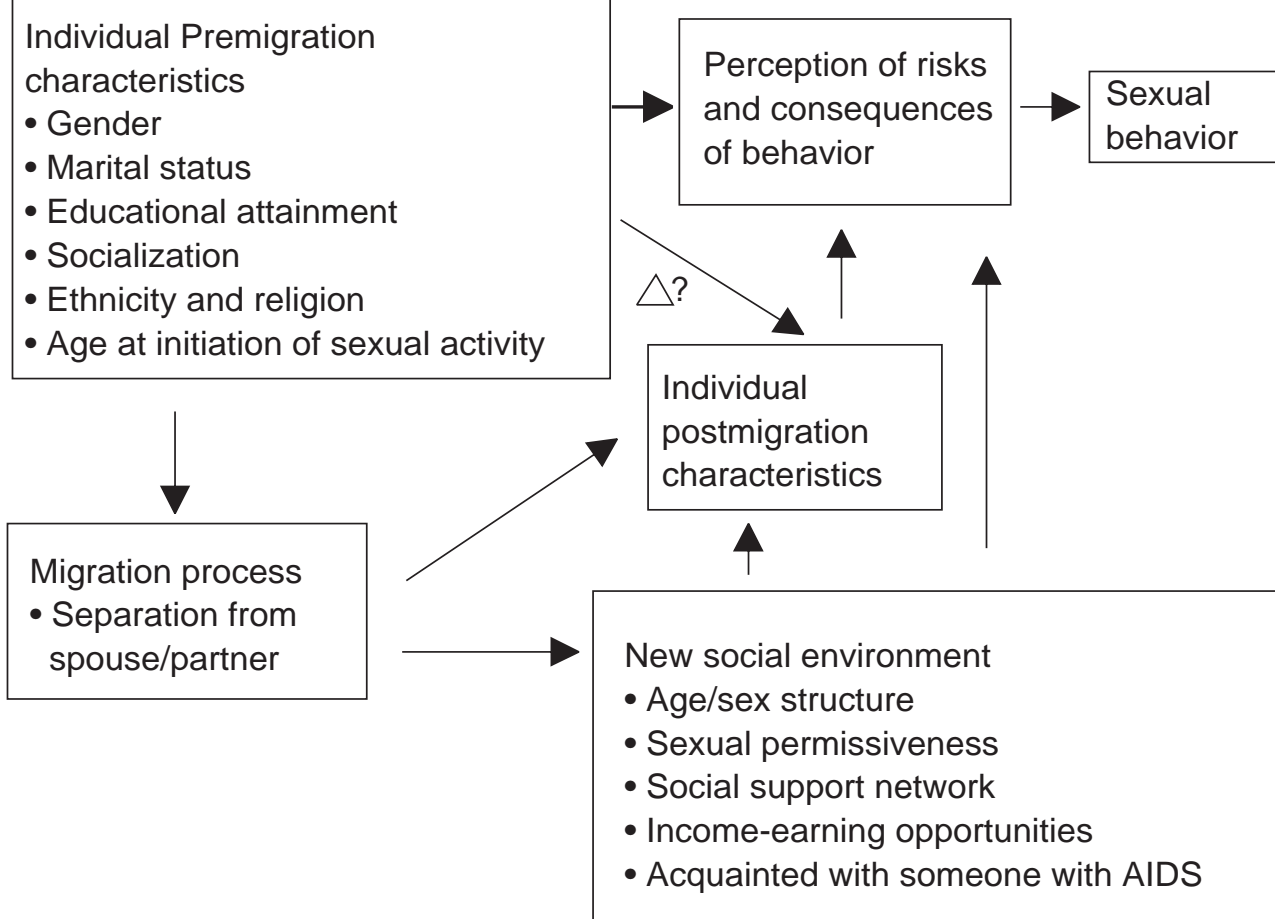


Migrants may be predisposed toward riskier sexual behavior than others in their new social settings owing to personal traits established before migration. The act of voluntary movement - often over long distances, between radically different socio-cultural environments, and with uncertain consequences and support networks at destination - defines migrants, to a greater or lesser degree, as innovators or "risk-takers." This perspective of migrants was articulated in early theories of migration (for instance, Petersen 1958) and remains popular today (see Massey et al. 1994 for a review). Indeed, econometric studies of migrant behavior routinely attribute outcomes different from those affecting nonmigrants to migrants" "unobservable" risktaking tendencies or characteristics (Moreno 1994; Rosenzweig and Wolpin 1988). Heightened risk-taking behavior conceivably applies to other aspects of migrants' lives, including their sexual conduct early in life and in postmigration settings. If so, then migrants should be more likely than nonmigrants to engage in unprotected sex with multiple partners at areas of destination, regardless of their gender or the presence of a regular sexual partner (such as a spouse).

Historically, especially during the colonial period, the selectivity of migration to economic centers of East and Southern Africa was based on sex and age: migrants were overwhelmingly young males, typically between ages 15 and 30, in search of income to pay taxes or to support kin (or alternatively, recruited to fulfill labor demand) (Iliffe 1987). Since the 1960s, however, with the relaxation of former colonial restrictions on urban residence, women have comprised a growing proportion of migrants from the countryside (Becker, Hamer, and Morrison 1994; Hugo 1993; Peil 1985). Substantial expansion of education in the Kenyatta years has also influenced who 
migrates to urban centers: increasingly, persons who wish to capitalize on rural schooling, who seek higher education opportunities (Oucho and Gould 1993), or whose education best positions them to pursue household survival strategies (Findley and Williams 1991). For young women, economic or educational motivations to migrate may necessitate reliance on men, usually older men, for sufficient income (Caldwell, Caldwell, and Quiggin 1989). For other women who migrate to economic centers without an education, marketable skills, or knowledge of available income-earning opportunities, informal or formal prostitution is one of the means immediately available to earn sufficient money for self-support and to send remittances to relatives in the countryside (Anarfi 1992; Rodenberg 1993). In the past, resort to commercial sex has been most common among divorced or separated migrant women (Caldwell, Caldwell, and Quiggin 1989; Caldwell, Anarfi, and Caldwell 1997; Orubuloye, Caldwell, and Caldwell 1992). However, it is probable that the financial dependency of young female migrants also makes them vulnerable candidates for casual relationships in the urban sexual market.

Changes in sexual practice wrought by the migration process itself may play a role in HIV transmission. The most commonly cited postmigration characteristic affecting sexual behavior is separation from a regular sexual partner/spouse (Sanders and Sambo 1991). As Packard and Epstein (1992:338) assert with respect to East Africa, "women left alone at home for long periods of time may take on 'lovers'; and men may take on second 'wives' near their place of employment." Indeed, there is anthropological evidence in East Africa that adultery by husbands and wives is tolerated if the husband is away for long periods of time, even if it is not acknowledged explicitly (Caldwell, Caldwell, and Quiggin 1989:213; Lurie et al. 1997:24- 
25; Romero-Daza 1994). For men whose occupation involves long periods of spousal separation and travel over wide geographical areas, mainly truckers and their assistants, commercial sex is common, condom use is rare, and perceived risks of HIV contraction and of subsequent death are guided by ignorance. Conover (1993:68) quotes one Kenyan trucker as saying, "if you sleep with a virgin it will often take away your AIDS." As a result of such misconceptions, there is relatively high prevalence of HIV-1 seropositivity among these migrants: for example, 35 percent of transporters working out of the port of Mombasa (Carswell, Lloyd, and Howells 1989). While there are obvious reasons to expect that having multiple sexual partners is more likely when there is separation from a regular sexual partner, such behavior may also depend on the geographical distance involved in the move; a maxim in sociology, attributed to Robert Park, is that "spatial distance reflects social distance." Thus, where the change in socio-cultural environment is greater, as in the case of resettlement from a remote village to Nairobi, one would expect stricter adherence to traditional notions of fidelity in the absence of the spouse or regular partner.

A third mechanism linking migration with sexual behavior points to the social milieu in which the individual is living. The WHO's Global Programme on AIDS survey in Kenya found that the mean number of casual sex partners was almost twice as high in urban settings as in rural ones, regardless of marital status (Carael et al. 1992). Accordingly, the prevalence of AIDS is reported to be four to ten times higher in urban than in rural areas of Africa (Caldwell, Anarfi, and Caldwell 1997:44). Migrants may contribute to these differentials. Some authors argue that rural-urban migration in Africa leads to the removal of village controls over sexual behavior and 
often places a person in an environment conducive to high-risk behaviors (Anarfi 1993; Decosas et al. 1995). This assertion could be extended to include rural migrants to economic centers in the countryside. Contextual effects such as the sex and age ratios at the place of destination - largely a product of net migration - may also have a marked effect on migrants' sexual practices (Quinn 1994). Hunt (1989) describes specific instances where the forced concentration of male migrant laborers in rural extraction industries inevitably fed demand for migrant female sex workers, with catastrophic results for the spread of venereal diseases in migrant-populated areas. An identical process, based on the continued imbalanced age/sex ratio of migrant laborers, has been cited for the spread of AIDS in contemporary African cities (Decosas and Pedneault 1992; Larson 1989). Other important contextual effects likely to influence migrants' sexual behavior are the types of social networks in which migrants are involved. Common assumptions of AIDS prevention programs are that knowing someone who has or has died of AIDS, or knowing how to protect oneself from HIV infection, raises awareness of HIV/AIDS and leads to behavioral change (National Research Council 1996). Migrants from rural areas are presumably disadvantaged in both these respects, insofar as AIDS awareness and condom use are less prevalent in rural Kenya (National Council for Population and Development 1994).

Underlying the relationship between migration and high-risk sexual behavior are substantial gender differences in sexual behavior; namely, having multiple sex partners is far more predominant among men than among women. Men have a stronger cultural prerogative than women in initiating and negotiating sexual relationships. The recent WHO/GPA survey in Kenya indicated that 32 percent of sexually active Kenyan men and 11 percent of 
sexually active Kenyan women had casual or commercial sex in the last 12 months with someone other than their regular partner. Similarly in Tanzania, only about 20 percent of unmarried women had multiple partners, as compared to almost one-half of unmarried men (Rutenberg, Blanc, and Kapika 1994). Reasons given for men's multiple partnering are typically biological - their pursuit of sexual pleasure or their drive for sex - whereas an economic rationale is usually applied to women. Women working outside the home, such as in market vending, may exchange sex for money intermittently or "on the side" - informal prostitution that also involves the exchange of sex for material goods or lodging and not for money alone (RomeroDaza 1994; Sanders and Sambo 1991; Wilson, Armstrong, and Lavelle 1991). Risks posed by multiple partnering are exacerbated by the fact that women, in commercial sex relations and even with their own spouse, are at a disadvantage in protecting themselves from disease by demanding condom use by a male partner (Dixon-Mueller 1993; Knodel and Pramualratana 1995). These gender-based differences underscore the importance of examining migration-AIDS relationships separately for women and men.

Recent research on sexual behavior has begun to emphasize the character of sexual networks (Orubuloye et al. 1994). A guiding assumption has been that it is not so important how many sexual partners an individual has, but who those sexual partners are. For example, if a man has four sexual partners and the sexual network is closed, he is far less exposed to the risk of STD or HIV infection than a man who has one partner who belongs to an open sexual network of many other partners. Our data do not contain information about characteristics of the sexual network. Nevertheless, while these characteristics have been shown to be important, we view such information 
as permitting further refinement of the study of risky sexual behavior. Moreover, information about a sexual network does not provide prima facie evidence of the risk of exposure to HIV/AIDS. Sometimes the lack of information is evidence of risky sexual behavior. For example, in a study of Nigerian men in one urban area, more than 90 percent reported having current extramarital sex, yet only one-third of these men could identify their extramarital partners' partners (Orubuloye, Caldwell, and Caldwell 1992).

\section{DATA, VARIABLES, AND METHODS}

The breadth of information gathered by the 1993 Kenya Demographic and Health Survey (KDHS), its sampling procedure, and its large sample size provide an unprecedented opportunity to examine in detail some of the contextual and behavioral correlates of HIV transmission at a national level in Africa, as well as by urban and rural environments and among persons exposed to both types of environments. The KDHS, sponsored by USAID, collected data on migration, AIDS knowledge, sexual activity, family planning, and socioeconomic conditions from 7,540 women and 2,336 men of reproductive age. Stratified sampling was employed to provide data that are representative of the national population and of residents of rural and urban areas (the latter defined as having populations of 10,000 or more, plus all 48 district headquarters regardless of size). Migrants were identified on the basis of questions on duration of residence at the current locale and type of previous residence. Persons who had ever resided in a "community" other than the current one for a period of six months or more are considered lifetime migrants. The generally high reliability of information garnered from 
such basic questions on residence has been discussed elsewhere (Bilsborrow, Oberai, and Standing 1984).

The most valuable DHS data for examining HIV risks in Africa, those pertaining to sexual practices, have been criticized as potentially invalid as a result of misreporting among respondents (Caldwell, Caldwell, and Quiggin 1989). Similar concerns were expressed 20 years ago regarding the collection of fertility and family planning data in cross-national survey projects and were proved overstated (Dare and Cleland 1994). Common critiques are that commercial sex workers and clients with numerous liaisons are likely to report rounded numbers of recent partners; men may inflate (and women underreport) extramarital behavior in response to the cultural acceptability of such behavior; and frequency of sex is highly subject to response error over longer recall durations (Rutenberg, Blanc, and Kapika 1994). We address such problems through two analytic strategies: 1) conducting separate analyses for men and women, with controls for characteristics, such as marital status and age, most likely to affect the reliability of reporting; and 2) defining high-risk sexual behavior, our dependent variable, simply as having had more than one partner in the last six months and not having used a condom with any partner, while taking account of persons in polygamous unions. We assume that all persons in our study are able to remember whether or not they have had more than one recent partner over a six-month period, and that motivations to misrepresent the number of sexual partners or condom use are primarily a result of gender and hence will not bias our results. As noted above, we cannot determine the identity of sexual partners (spouse, regular lover, or commercial sex worker) from the DHS, as has been attempted in small-scale field studies in Africa (Caldwell, Caldwell, and Quiggin 
1989; Orubuloye, Caldwell, and Caldwell 1992), nor the physical susceptibility of respondents to contracting the virus (for instance, as a result of genital lesions). Inasmuch as these factors are critical sexual parameters of HIV infection, our analysis provides a broad test of the relationship between migration and high-risk sexual behavior.

Table 1 describes the independent variables used in the analysis. The dichotomous dependent variable is a composite of two behaviors: multiple partnering and condom use. Migrants are categorized according to settlement type of origin and destination, and by sex, each of which is expected to have a distinct influence on behavior. Differences in the size of each migrant group in Kenya (with men and rural origins and destinations predominant) have implications for the substantive significance of findings. While migrants' duration of residence is likely to affect sexual behavior through socialization processes, access to income and information, and other means, this variable is not included because of its high correlation with age. Other explanatory variables are chosen to determine whether migrant status has an independent effect on sexual behavior (including condom use) in urban and rural areas after accounting for 1) personal characteristics ascribed or established premigration, mainly at birth or during childhood (and therefore presumably less influenced by current health program interventions than by policies or conditions that influence migrant selectivity in origin areas); 2) marital and cohabitation status, which commonly changes as a result of migration and is likely to dictate strongly the level of sexual activity; and 3) the social environment in which migrants reside, as measured by area of residence and familiarity with HIV/AIDS. We restrict the number of variables representing these factors in our analysis (at the risk of model misspecification) mainly because of the high correlation observed between some of 


\section{Table 1 Variables in the analysis of high-risk sexual behavior ${ }^{\mathrm{a}}$ (Kenya,}

1993)

Variables

\section{Migrant Status}

Urban residence

Rural residence

\section{Personal Characteristics}

Age

Marital status

Education

Early initiation of sexual activity

Ethnicity

Religion

Land ownership (women only)

High-risk occupation (men only)

\section{Social Environment Characteristics}

Residence in major city (urban sample only)

Acquainted with an HIV-infected person

Believes you can protect against AIDS

\section{Categories ( $0=$ reference category $)$}

$0=$ Nonmigrant

$1=$ Urban-urban migrant

$2=$ Rural-urban migrant

$0=$ Nonmigrant

$1=$ Urban-rural migrant

$2=$ Rural-rural migrant

$0=$ Age 30 years or older

$1=$ Age 20 to 29 years

$2=$ Age less than 20 years

$0=$ Monogamous $/$ co-resident with spouse

$1=$ Never married

$2=$ Formerly married

$3=$ Polygamous/ co-resident with spouse

$4=$ Polygamous/ living apart from spouse

$5=$ Monogamous/ living apart from spouse

$0=$ Less than a secondary school education

$1=$ Secondary school education or higher

$0=$ Did not initiate sex before age 15

$1=$ Initiated sex before age 15

$0=$ Other ethnic group

1 = Kikuyu

$0=$ Other religious affiliation

$1=$ Muslim

$0=$ Owns land

$1=$ Does not own land

$0=$ Other occupation/ no work

$1=$ Trucker

$0=$ Residence outside of major city

$1=$ Residence in Nairobi or Mombasa

$0=$ No

$1=$ Yes

$0=\mathrm{No} /$ Don't know

$1=$ Yes

${ }^{a}$ High-risk behavior is defined as two or more sexual partners in previous six months and non-use of a condom with any partner. For polygamous men, the number of multiple partners must exceed the number of wives. 
these variables and other potential predictors of sexual behavior (for example, knowledge of modes of HIV transmission).

Logistic regression analysis is applied to four models, representing men and women residing in urban and rural areas. Separate models are required to determine the extent to which the effects of migration and migrant status are a function of gender and social environment, and consequently the importance of different types of migration to the potential spread of HIV. Persons whose migration status (whether they ever migrated) is unknown are excluded from the analysis; they represent less than 1 percent of the KDHS samples of both women and men. Persons recorded as "visitors" (who have resided in the current locale for less than six months but do not intend to settle there) are classified as migrants, since they have, in fact, experienced geographic mobility and their place of residence in the future remains unknown.

\section{DESCRIPTIVE RESULTS}

Table 2 shows that migrants and nonmigrants in Kenya differ in their sexual behavior and levels of HIV/AIDS awareness, although there is no universal pattern that distinguishes migrants from nonmigrants across gender and place of residence. On the whole, migrants do not exhibit exceptionally high-risk sexual practices, though this may be due to personal characteristics (notably, higher levels of marital union and educational attainment) that generally distinguish them from nonmigrants in Kenya, and that also typically inhibit high-risk sexual behavior. In urban areas, a higher percentage of migrant than nonmigrant women of reproductive age are currently married and co-residing with a spouse or partner ( 52 percent of migrants, as 
compared to 35 percent of nonmigrants), and migrants are slightly older on average. Male migrants in urban areas are sexually active at an earlier age (24 percent had sex before age 15 , as compared to 10 percent of nonmigrants), and are more aware of protection against sexually transmitted disease than are nonmigrant men (at 91 and 80 percent, respectively). These differences in preventive knowledge are probably associated with the observed much higher level of education among urban migrant men. Yet higher levels of educational attainment and knowledge of AIDS transmission among migrant men do not seem to lead to more cautionary sexual practices.

In rural Kenya, differences are more apparent. Although migrant women initiate sex at a later age than nonmigrants, and are less likely to have had sex before age 15, migrants have more lifetime sex partners (although this is probably associated with their older average age). Rural migrant women also have greater familiarity with the consequences of high-risk sexual behavior: a larger percentage know someone who has AIDS or has died of the disease and perceive themselves to be at risk of acquiring AIDS. There are similar differences among men in rural Kenya. Male migrants show signs of greater sexual networking over their lifetimes, but again, they are not more disposed than nonmigrant men to engage in unprotected sex with multiple partners. The statistics indicate that male migrants have fewer misconceptions about routes of transmission than their nonmigrant counterparts, as well as higher educational attainment, which may explain similar tendencies of risky behavior among rural migrant and nonmigrant men despite migrants' apparent greater involvement in sexual networks.

The KDHS data consist of independent samples of men and women; wives were asked few questions about their husbands. Figure 2 further ex- 


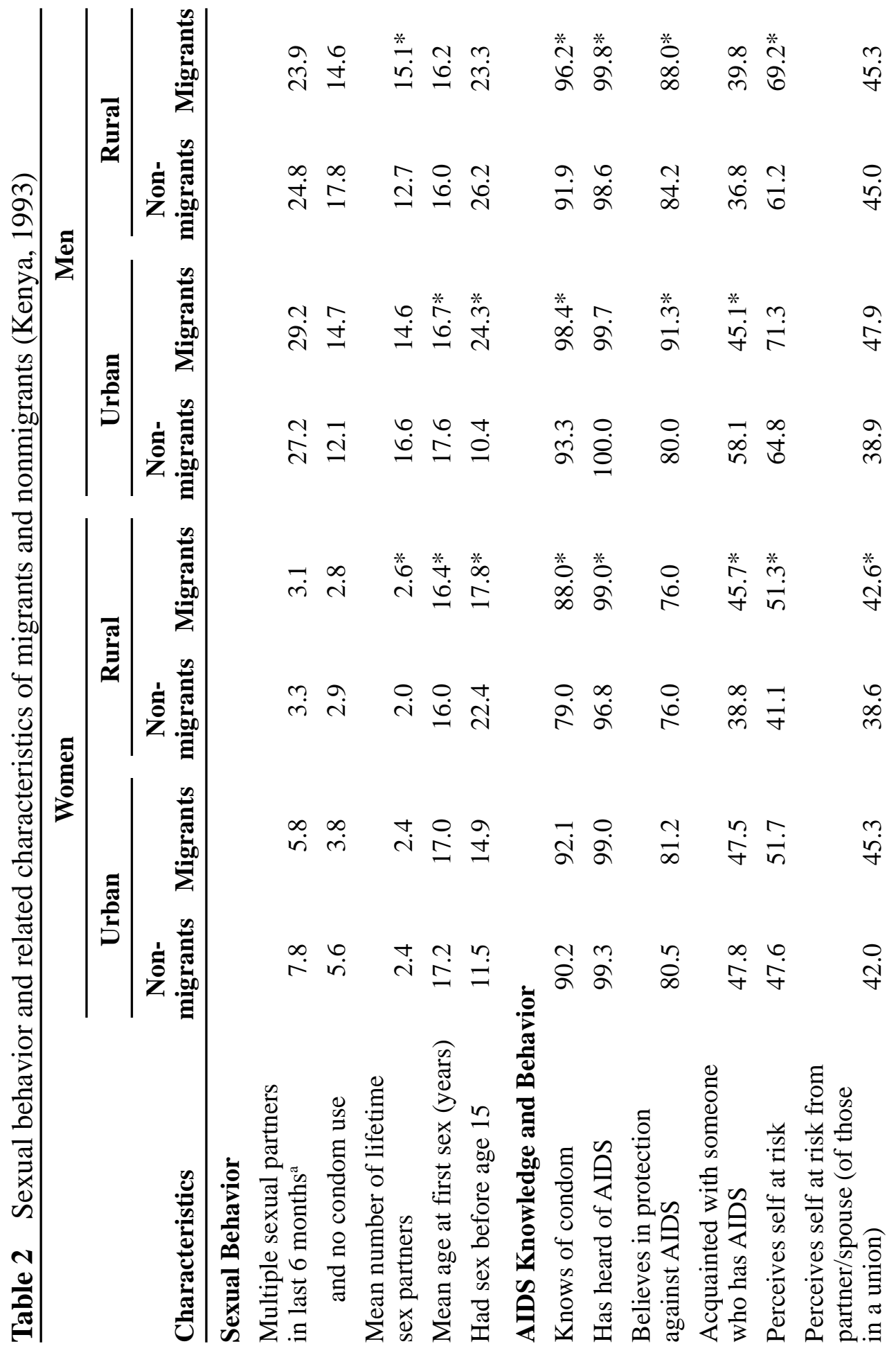




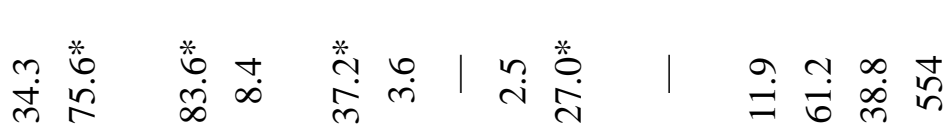

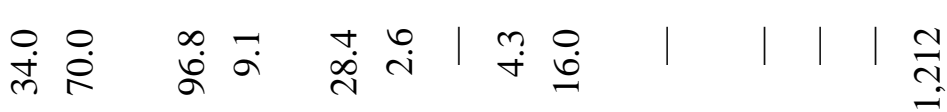

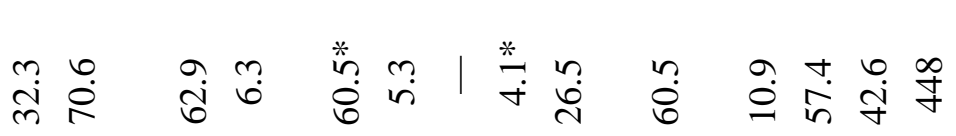

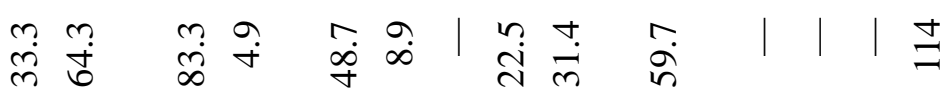

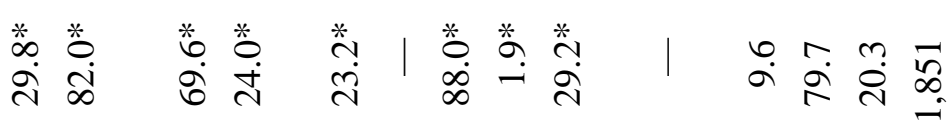

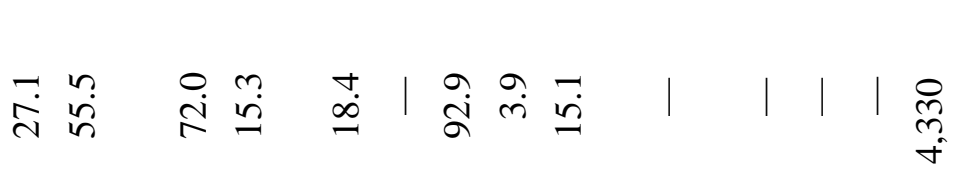

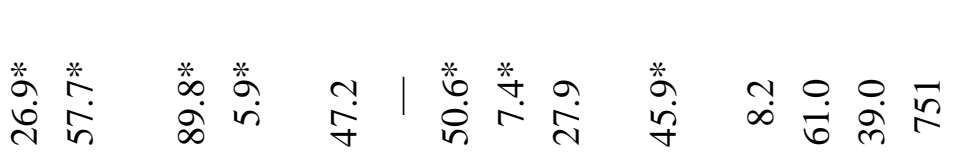

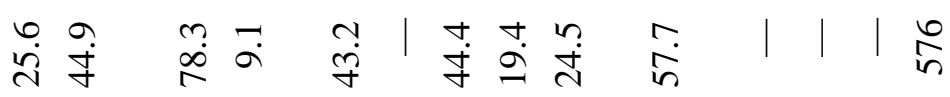
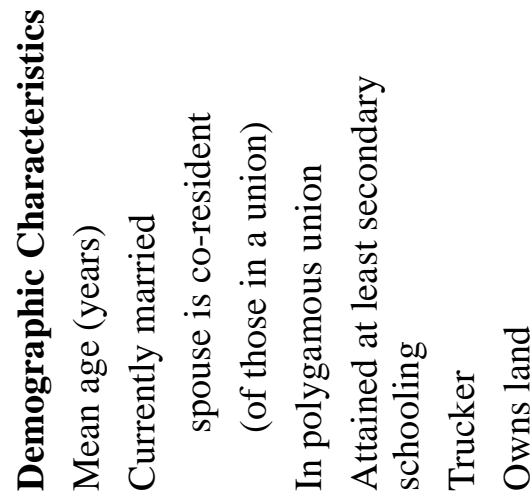

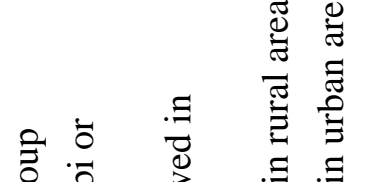

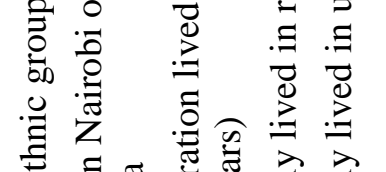

Ð্]

苛

离

常

巳

ฮี

อ

它

ํำ 
amines the relationship between migration and risk of HIV/AIDS, utilizing the limited information linking husbands and wives in the KDHS. The figure focuses on women's perceptions of risk of HIV/AIDS by whether or not a husband or partner is co-resident (similar data are available for men but the small number of cases makes the comparisons by presence of spouse/partner unreliable). Results show that rural women whose husbands or partners do not coreside with them are more likely both to perceive themselves at risk of HIV/AIDS in general, and to perceive themselves at risk in relation to behaviors of their husbands or partners. There are no statistically significant

Figure 2 Women's perceived risk of AIDS by residence and presence of husband/partner

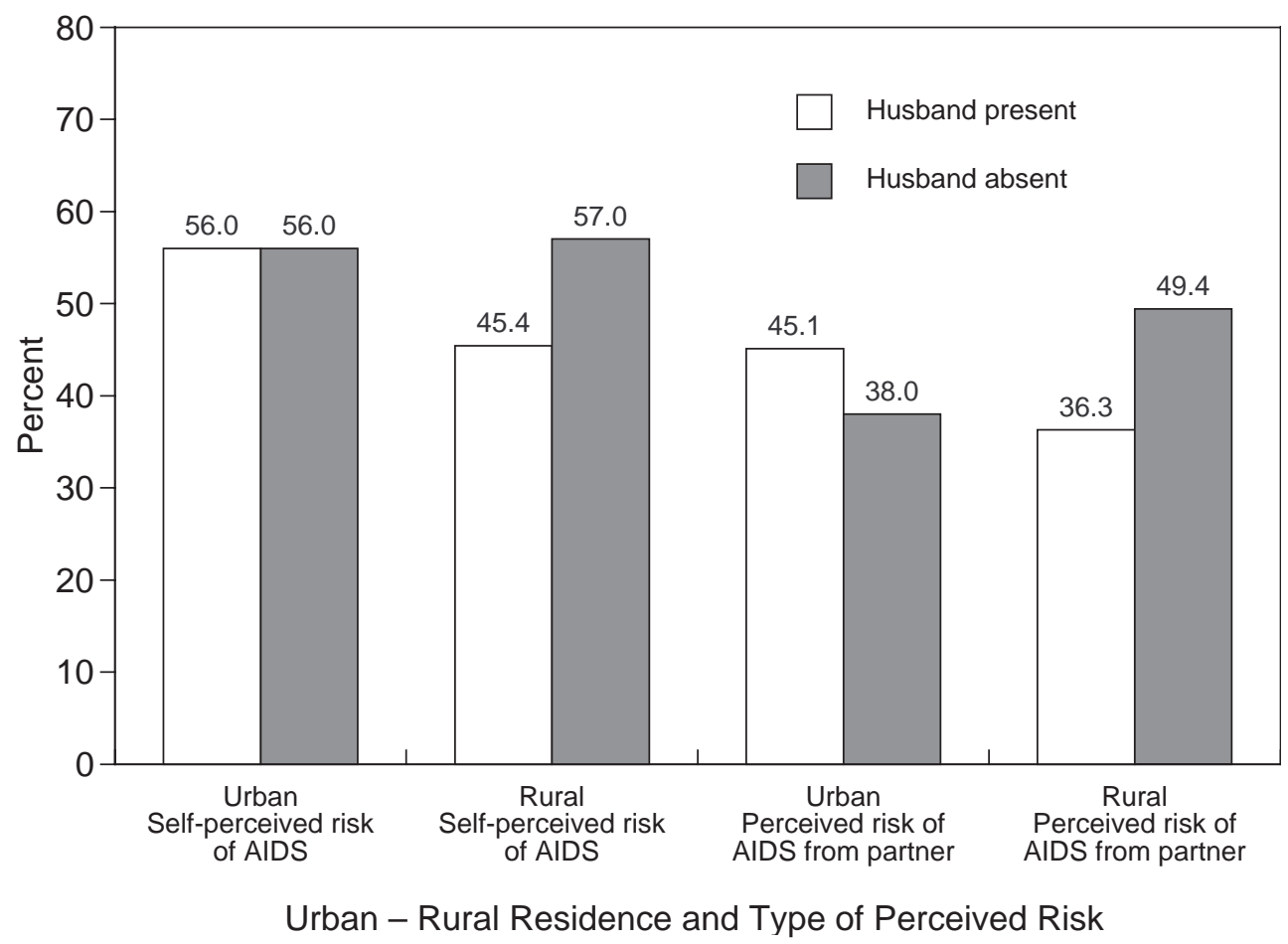


differences among urban women. These results can be interpreted as supporting the argument that HIV/AIDS will move into lower HIV-prevalence rural areas by way of migrant husbands who return to their wives and have unprotected sex.

\section{MULTIVARIATE RESUlTS}

Table 3 presents results of the multivariate analysis. To simplify discussion, parameter estimates are exponentiated and presented as odds ratios. A ratio of 0.65 , for instance, indicates a 35 percent lower probability of engaging in high-risk sexual behavior (that is, having had two or more partners in the past six months and not having used a condom with either) than the reference group (whose odds are normalized at 1.00); a ratio of 1.40 means a 40 percent greater likelihood of high-risk sexual activity. Since the subsamples of urban residents, particularly of men, are relatively small, estimated effects of some variables in the urban models are unreliable even though their large size suggests an association with high-risk sexual behavior.

Migrant status has a complex relationship with high-risk sexual behavior net of other factors. Migration of women within rural Kenya may be a critical factor in the diffusion of HIV, although this does not appear to be the case with men. Women who migrate between rural areas (the dominant stream of mobility for women throughout sub-Saharan Africa) exhibit highrisk sexual behavior, with odds more than two-thirds higher (at 1.71) than rural nonmigrant women. This finding may reflect a large volume of movement to rural road sites and trading centers for commercial sex transactions, as documented in neighboring countries (Sewankambo et al. 1994). Other explanations may be that female migration in rural Kenya simply increases 
Table 3 Odds of engaging in high-risk sexual behavior ${ }^{\mathrm{a}}$ (Kenya, 1993)

\begin{tabular}{|c|c|c|c|c|}
\hline \multirow[b]{3}{*}{ Variables } & \multicolumn{4}{|c|}{ Models } \\
\hline & \multicolumn{2}{|c|}{ Urban } & \multicolumn{2}{|c|}{ Rural } \\
\hline & Women & Men & Women & Men \\
\hline \multicolumn{5}{|l|}{ I. Migrant Status } \\
\hline Nonmigrant & 1.00 & 1.00 & 1.00 & 1.00 \\
\hline \multicolumn{5}{|l|}{ Migrant } \\
\hline Urban-Urban & $0.47 *$ & $2.18 *$ & - & - \\
\hline Rural-Urban & $0.71 *$ & 1.24 & - & - \\
\hline Urban-Rural & - & - & $1.47 *$ & $1.38 *$ \\
\hline Rural-Rural & - & - & $1.71 *$ & 0.70 \\
\hline \multicolumn{5}{|l|}{ II. Personal Characteristics } \\
\hline Age 30 years or older & 1.00 & 1.00 & 1.00 & 1.00 \\
\hline Age less than 20 years & 0.89 & - & 0.83 & - \\
\hline Age 20 to 29 years & $2.13 *$ & 0.99 & 1.07 & $1.41 *$ \\
\hline Monogamous / co-resident & 1.00 & 1.00 & 1.00 & 1.00 \\
\hline Never married & $2.95 * *$ & $2.20 *$ & $8.10 * *$ & $1.79 * *$ \\
\hline Formerly married & $4.96 * *$ & 1.73 & $4.84 * *$ & 1.06 \\
\hline Polygamous / co-resident & 2.62 & 0.00 & $2.60 * *$ & $0.40 * *$ \\
\hline Polygamous / living apart & 4.74 & 1.52 & 0.12 & 0.75 \\
\hline Monogamous / living apart & 2.92 & 1.39 & 1.65 & 1.20 \\
\hline Less than secondary school & 1.00 & 1.00 & 1.00 & 1.00 \\
\hline Secondary school or higher & 0.62 & $0.44 * *$ & $0.44 * *$ & 0.84 \\
\hline Initiated sex before age 15 & $3.46 * *$ & 1.20 & $2.40 * *$ & $1.41 *$ \\
\hline Did not have sex before age 15 & 1.00 & 1.00 & 1.00 & 1.00 \\
\hline Other ethnic group & 1.00 & 1.00 & 1.00 & 1.00 \\
\hline Kikuyu & 0.55 & 1.13 & $0.47 * *$ & 0.99 \\
\hline Muslim & $0.16^{*}$ & 1.36 & 1.31 & $2.20 * *$ \\
\hline Other religion & 1.00 & 1.00 & 1.00 & 1.00 \\
\hline Trucker & - & $2.58 *$ & - & 0.66 \\
\hline Other occupation/ no work & - & 1.00 & - & 1.00 \\
\hline Does not own land & 1.04 & - & $2.67 * *$ & - \\
\hline Owns land & 1.00 & - & 1.00 & - \\
\hline \multicolumn{5}{|l|}{ III. Social Environment Characteristics } \\
\hline Currently lives in Nairobi or Mombasa & 1.00 & 0.66 & - & - \\
\hline Currently lives outside major city & 1.00 & 1.00 & - & - \\
\hline Acquainted with an HIV-infected person & 0.68 & 0.92 & $1.50 * *$ & 0.87 \\
\hline Not acquainted & 1.00 & 1.00 & 1.00 & 1.00 \\
\hline Believes in protection against AIDS & 1.00 & $0.43 * *$ & $0.64 * *$ & 0.57 \\
\hline Does not know of or believe in protection & 1.00 & 1.00 & 1.00 & 1.00 \\
\hline Constant & $-3.68 * *$ & $-1.27 *$ & $-3.81 * *$ & $-1.37 * *$ \\
\hline Model $X^{2}$ & $59.54 * *$ & $44.30 * *$ & $173.37 * *$ & $81.71 * *$ \\
\hline Number & 1,150 & 477 & 6,365 & 1,852 \\
\hline
\end{tabular}

${ }^{a}$ High-risk behavior is defined as two or more sexual partners in previous six months and non-use of a condom with any partner. For polygamous men, the number of multiple partners must exceed the number of wives.

$* .01<\mathrm{p}<.05 \quad * * \mathrm{p}<.01$ 
exposure to potential sexual partners while removing behavioral constraints imposed by family or the home community (that is, rural migrant women are selective according to sexual preferences or intentions); that movement away from kin reduces women's leverage in sexual negotiation; or that mobility results in reduced awareness of, or access to, sources of family planning, including condoms, at destination. These and other speculations warrant consideration in further explorations of this relationship.

Migration to urban areas shows an opposite relationship by gender. Urban migrant women, especially those from other urban areas, are less likely to engage in high-risk sexual behavior than are urban nonmigrants. The direction of the effect certainly undermines the argument that some women are motivated by economic plight in rural Africa to migrate to urban centers and pursue commercial sex as a survival strategy (Anarfi 1993; Larson 1989). In contrast, men who migrate between urban areas (who represent almost half of urban male migrants) are more than twice as likely to be involved in high-risk sexual activity than their urban nonmigrant counterparts, with odds of 2.18. Data on occupation available from the male surveys of the KDHS show that these men are commonly "white-collar" professionals, whose higher and more stable income may facilitate procurement of sexual partners. Given the continued predominance of men in the large volume of migration to urban Kenya (Hugo 1993), high levels of sexual networking among urban migrant men (29 percent had two or more recent partners, as compared to only 6 percent of urban migrant women), and generally low levels of condom use, this result has ominous implications for AIDS transmission in urban areas. Risky behavior among urban-urban migrant men is particularly noteworthy, as an increasing proportion of migrants will inevitably come from urban areas as Kenya continues to urbanize rapidly. 
More permissive sexual behavior in urban areas appears to be transmitted to rural areas by both female and male urban out-migrants. Among urban-rural migrants, women are 47 percent more likely, and men 38 percent more likely, to engage in high-risk sexual behavior in the countryside than are nonmigrants. Again, this supports the notion that traditional patterns of circular or return migration to rural destinations will likely diffuse HIV and AIDS throughout the countryside. One might add that these comparisons of lifetime migrants (characterized by their place of last residence) with nonmigrants do not allow for the multiplicity of moves a migrant usually makes, especially in circular migration. Insofar as circular rural-urbanrural migration in Kenya remains common and frequent, and rural nonmigrants are socialized by the experience of migrants, one would particularly expect HIV seroprevalence levels in rural Kenya to rise substantially in coming years. This would especially be the case if condom use in rural Kenya - currently estimated at about 1 percent of women and 6 percent of men - remains low.

With respect to other variables in the models, most effects are as expected. While we observed that migrants have distinct patterns of sexual behavior that are independent of their generally high levels of spousal separation, cohabitation and marital status strongly dictate sexual practice. In both urban and rural areas, single men and women are much more likely to engage in risky sexual behavior than are monogamous, co-resident men and women. This finding merits attention given the preoccupation of researchers with high levels of extramarital sex in Kenya (Carael et al. 1992), and the comparative absence of research on the sexual practices of never-married persons. Nonmarried status is much more closely related to high-risk practices than is age, with teenagers as a whole seemingly not a high-risk group. 
Persons with higher education have much lower odds of risky behavior than others, although separate analysis (not shown) indicates that for women and men in both settlement types this reflects only much higher condom use (in relative terms) among those with advanced schooling, not significant differences in numbers of recent sexual partners. Men and women initiating sex at an early age (less than 15 years) are much more likely to be currently engaged in high-risk sexual behavior, indicating the strength of sexual initiation as a predisposing factor for later sexual behavior. The low estimate for Kikuyu women in rural areas is likely capturing geographic effects, as the rural Kikuyu are highly concentrated in the Nairobi district and Central Province, in "urbanized" villages where condom use is more prevalent than elsewhere in the country. As documented by Carswell, Lloyd, and Howells (1989) and others (Bwayo et al. 1991), men working as truckers (or their helpers) engage in very high-risk sexual behavior in urban areas, with odds of 2.58 as compared to 1.00 among resident urban men. Of interest here is that this appears unrelated to truckers' migrant status; it is not simply because these men are "passing through" that they behave as such. Finally, economic vulnerability predisposes rural women to risky sexual behavior, perhaps including participation in commercial sexual networks at rural road and work sites. Rural women who do not own land are almost three times more likely than others to exhibit high-risk behavior.

Social environment has some effect on sexual practices, although it defies easy interpretation. As compared to smaller urban areas, residence in Kenya's two largest cities, Nairobi and Mombasa, shows no independent effect on high-risk behavior. Rural women who are personally acquainted with someone who has or has died of AIDS are 50 percent more likely to have risky sexual practices than are other rural women, reflecting the selec- 
tivity of social interaction. While it is disturbing that such personal experience does not appear to modify the behavior of rural women, a more positive finding is that knowing there are means of preventing HIV-contraction (including through nonsexual behaviors) reduces the odds of risky sexual behavior among women in rural areas and among men in urban areas. Additional analysis (not shown) indicates that, for both sexes, this result is consistent with both greater condom use and fewer sexual partners among these persons.

\section{DISCUSSION AND CONCLUSION}

We have explored whether the information on geographic mobility and sexual practices collected by the Demographic and Health Surveys in many African countries can illuminate relationships between migration and risks of HIV infection at the national level, using the example of Kenya. Such an undertaking is necessary because mapping and containing the spread of disease in Africa involves following numerous forms of population movement (Prothero 1977), and noting culturally specific and relevant policy and program strategies for different populations. While our study provides evidence of a positive relationship between migration and high-risk sexual behavior in Kenya, it shows that this relationship is not consistent across gender or different migrant flows. Allowing for data limitations, the evidence we have presented suggests that health interventions should follow two paths: 1) target specific groups of migrants (broadly, men in urban areas, women in rural areas, and persons moving from urban to rural areas) and 2) focus on spouses and partners of migrants, especially of male migrants, and their ability to negotiate safe sexual practices. 
It has been noted that HIV diffusion in East Africa has resulted mainly from a large excess of males among sexually active adults in cities-a residual consequence of colonial policies to restrict family migration to economic centers (Caldwell, Anarfi, and Caldwell 1997). Single male laborers have traditionally relied on female sex workers for gratification, as well as to relieve feelings of loneliness-with catastrophic repercussions for the spread of sexually transmitted disease. Consequently, with reference to AIDS containment in sub-Saharan Africa, Decosas and Pedneault (1992) suggest adopting migration policies that encourage the movement of families rather than male workers alone. They argue that maintaining male migrants in rural labor camps and urban slums may be a far more costly prevention strategy than accommodating the movement of migrant men with their families. Inasmuch as policies and measures to influence migration patterns in Kenya are effective at all - as they have not been in the postcolonial era - our findings partly support this recommendation. Urban women and men separated from their spouses appear much more likely to engage in high-risk sexual behavior than cohabitants in urban areas, although these results are based on small samples and are not statistically significant. Monogamous couples in rural areas exhibit a similar pattern. However, given the extremely risky behavior of never- and formerly married persons in both urban and rural areas - and the large minority of adults in Kenya who are not married - it deserves consideration whether migration and spatial policies implemented to contain the geographic spread of AIDS should focus more on managing and accommodating the substantial mobility of single persons in Kenya, and pay less exclusive attention to migration patterns of married couples. 
Along with our multivariate findings, bivariate results of the perceived risk of HIV/AIDS among rural women indicate that AIDS will likely increasingly spread to rural areas because of return migration of male laborers from the cities. Very low condom use among married couples exposes rural wives of these male migrants to HIV due to unprotected sex with their infected husbands (French 1996). Some argue that since condom use among married couples is already low, since condoms are usually associated with extramarital sex, and since the suggested use of condoms by a spouse can lead to marital conflict given its association with commercial sex (Knodel and Pramualratana 1995), a more useful strategy is to promote condom use for extramarital sexual activity and not its use in general. Yet the relatively high HIV prevalence rates among pregnant women in sub-Saharan Africa argue for an intervention that can help those who are often "passively" exposed to AIDS through marital sexual intercourse.

Our findings also add to the substantial empirical evidence that expansion of formal education in low-income countries can have positive demographic consequences, in this case a decline in sexual activity that potentially increases the risk of HIV infection, and hence mortality, of women and men. Advocacy of female education in particular, a longstanding practice of demographers, is growing in the development field more generally (Summers 1994). While improvements in female schooling are obviously commendable for both demographic and other reasons, it is reported that the proportion of girls ages 6-11 enrolled in primary school in sub-Saharan Africa has declined from 59 to 51 percent in the 1980s (UNESCO 1994). In Kenya, many children now begin primary schooling as late as age 11 (Lloyd and Montgomery 1996). In light of the formidable economic, demographic, 
and political forces that appear to be constraining women's (and to a lesser extent men's) schooling - enormous foreign debt burdens, falling commodity prices, high fertility in recent years (resulting in young age structures), war in some countries - more immediate changes in AIDS-related behavior may result from efforts to promote knowledge and means of disease prevention through health and family planning programs. Since many migration streams are comprised of laborers with little schooling, special attention should be focused on public health campaigns that can be understood by those who are illiterate (women make up a disproportionate number in this category).

While our discussion of results contains speculation concerning migration-AIDS relationships, more definitive conclusions may derive from analysis of superior data, containing information on reasons for migration, household income, perception of cultural norms, frequency and duration of spousal separation, sex ratios at place of residence, and other information. More precise estimates of effects of migrant status might also be obtained through analytic techniques that control for the self-selection of migrants according to observable factors associated with sexual behavior, and that attempt to capture effects of unobservable migrant characteristics, such as a predisposition to risky behavior; such techniques are currently being refined. Nonetheless, it remains striking that several migration effects appear large even after accounting for such typically robust predictors of sexual partnering and risk-taking as marriage, age, education, and AIDS awareness. The implication is that migration is indeed an important factor in the spread of the AIDS virus in Kenya, and that reasons for this phenomenon deserve further scrutiny. 


\section{References}

Adepoju, A. 1984. "Issues in the Study of Migration and Urbanization in Africa South of the Sahara," in Population Movements: Their Forms and Functions in Urbanization and Development. P.A. Morrison, ed. Liege: Ordina Editions. 115-150.

Allen, S. et al. 1991. "Human Immunodeficiency Virus Infection in Urban Rwanda," Journal of the American Medical Association 266(12): 16571663.

Anarfi, J. 1992. "Sexual Networking in Selected Communities in Ghana and the Sexual Behaviour of Ghanaian Female Migrants in Abidjan, Côte d'Ivoire," in Sexual Behaviour and Networking: Anthropological and Socio-Cultural Studies on the Transmission of HIV. T. Dyson, ed. Liege: Derouaux-Ordina Editions. 233-248.

— 1993. "Sexuality, Migration and AIDS in Ghana-A Socio-Behavioral Study," Health Transition Review 3 (Supplement): 45-67.

Barongo, L.R. et al. 1992. "The Epidemiology of HIV-1 Infection in Urban Areas, Roadside Settlements and Rural Villages in Mwanza Region, Tanzania," AIDS 6: 1521-1528.

Becker, C.M., A.M. Hamer, and A.R. Morrison. 1994. Beyond Urban Bias in Africa: Urbanization in an Era of Structural Adjustment. Portsmouth, NH: Heinemann.

Bilsborrow, R.E., A.S. Oberai, and G. Standing. 1984. Migration Surveys in Low-Income Countries: Guidelines for Survey and Questionnaire Design. London: Croom Helm.

Brockerhoff, M. 1995. "Fertility and Family Planning in African Cities: The Impact of Female Migration," Journal of Biosocial Science 27: 347358. 
Bwayo, J.J. et al. 1991. "Long Distance Truck Drivers: 1. Prevalence of Sexually Transmitted Diseases (STD)," East African Medical Journal 68(6): 425-429.

Caldwell, J.C., P. Caldwell, and P. Quiggin. 1989. "The Social Context of AIDS in Sub-Saharan Africa," Population and Development Review 15(2): 185-234.

Caldwell, J.C., John K. Anarfi, and P. Caldwell. 1997. "Mobility, Migration, Sex, STDs, and AIDS: An Essay on Sub-Saharan Africa with Other Parallels," in Sexual Cultures and Migration in the Era of AIDS. G. Herdt, ed. New York: Oxford University Press. 41-54.

Carael, M., J. Cleland, J.C. Deheneffe, and L. Adeokun. 1992. "Research on Sexual Behaviour That Transmits HIV: The GPA/WHO Collaborative Surveys-Preliminary Findings," in Sexual Behaviour and Networking: Anthropological and Socio-Cultural Studies on the Transmission of HIV. T. Dyson, ed. Liege: Derouaux-Ordina Editions. 65-87.

Carswell, J.W., G. Lloyd, and J. Howells. 1989. "Prevalence of HIV-1 in East African Lorry Drivers," AIDS 3: 759-761.

Chirwa, W.C. 1997. "Migrant Labour, Sexual Networking and MultiPartnered Sex in Malawi," Health Transition Review, Supplement 3 to Volume 7: 5-15.

Conover, T. 1993. "Trucking Through the AIDS Belt," The New Yorker, 16 August: 56-75.

Dare, O.O. and J.G. Cleland. 1994. "Reliability and Validity of Survey Data on Sexual Behaviour," Health Transition Review, Supplement to Volume 4: 93-110.

Decosas, J. and V. Pedneault. 1992. "Women and AIDS in Africa: Demographic Implications for Health Promotion," Health Policy and Planning 7(3): 227-233. 
Decosas, J. et al. 1995. "Migration and AIDS," The Lancet 346(23): 826828.

Dixon-Mueller, R. 1993. "The Sexuality Connection in Reproductive Health," Studies in Family Planning 24(5): 269-282.

Findley, S. 1982. "Fertility and Migration," in International Encyclopedia of Population. J.A. Ross, ed. New York: The Free Press. 247-252.

Findley, S. and L.B. Williams. 1991. Women Who Go and Women Who Stay: Reflections of Family Migration Processes in a Changing World. World Employment Programme Research, Population and Labour Policies Programme, Working Paper No. 176. Geneva: International Labour Office.

Fontanet, A. and P. Piot. 1994. "State of Our Knowledge: The Epidemiology of HIV/AIDS," Health Transition Review, Supplement to Volume 4: $11-23$.

French, H.W. 1996. "Migrant Workers Take AIDS Risk Home to Niger," New York Times, 8 February: 3.

Goldstein, S. and A. Goldstein. 1982. "Techniques for the Analysis of the Interrelations Between Migration and Fertility," in United Nations, $\mathrm{Na}$ tional Migration Surveys Manual X: Guidelines for Analysis. New York: United Nations Economic and Social Commission for Asia and the Pacific. 132-162.

Gould, W.T.S. 1988. "Urban-Rural Return Migration in Western Province, Kenya," section 4.1.3. in African Population Conference 1988, Volume 2. Liege: IUSSP.

Hawkes, S.J. et al. 1994. "Risk Behavior and HIV Prevalence in International Travelers," AIDS 8: 247-252.

Hugo, G.J. 1993. "Migrant Women in Developing Countries," in Internal Migration of Women in Developing Countries. New York: United Nations. 47-73. 
Hunt, C.W. 1989. "Migrant Labour and Sexually Transmitted Disease: AIDS in Africa," Journal of Health and Social Behavior 30: 353-373.

Iliffe, J. 1987. The African Poor: A History. African Studies Series 58. Cambridge: Cambridge University Press.

Janz, N.K. and M.H. Becker. 1984. "The Health Belief Model: A Decade Later," Health Education Quarterly 11(1): 1-47.

Knodel, J. and A. Pramualratana. 1995. "Prospects for Increased Condom Use in Marital Unions in Thailand." PSC Research Report No. 95337. University of Michigan.

Larson, A. 1989. "Social Context of Human Immunodeficiency Virus Transmission in Africa: Historical and Cultural Bases of East and Central African Sexual Relations," Reviews of Infectious Diseases 11(5): 716731.

Lloyd, C.B. and M.R. Montgomery. 1996. "High Fertility, Unwanted Fertility, and Children's Schooling." Paper presented at the Annual Meeting of the Population Association of America, New Orleans, LA.

Lurie, M., A. Harrison, D. Wilkinson, and S.A. Karim. 1997. "Circular Migration and Sexual Networking in Rural Kwazulu/Natal: Implications for the Spread of HIV and Other Sexually Transmitted Diseases," Health Transition Review, Supplement 3 to Volume 7: 17-27.

Massey, D.S. et al. 1994. "An Evaluation of International Migration Theory: The North American Case," Population and Development Review 20(4): 699-751.

Moreno, L. 1994. Residential Mobility and Contraceptive Use in Northeastern Brazil. DHS Working Papers No. 9. Calverton, MD.: Macro International Inc.

National Council for Population and Development. 1994. Kenya Demographic and Health Survey 1993. Calverton, MD.: Macro International Inc. 
National Research Council. 1993. Demographic Change in sub-Saharan Africa. K.A. Foote, K.H. Hill, and L.G. Martin, eds. Washington, D.C.: National Academy Press.

- 1996. Preventing and Mitigating AIDS in Sub-Saharan Africa: Research and Data Priorities for the Social and Behavioral Sciences. B. Cohen and J. Trussell, eds. Washington, D.C.: National Academy Press.

Nunn, A.J., et al. 1995. "Migration and HIV-1 Seroprevalence in a Rural Ugandan Population," AIDS 9: 503-506.

Orubuloye, I.O., J.C. Caldwell, and P. Caldwell. 1992. "Diffusion and Focus in Sexual Networking: Identifying Partners and Partners' Partners," Studies in Family Planning 23(6): 343-351.

Orubuloye, I.O., J.C. Caldwell, P. Caldwell, and G. Santow. 1994. Sexual Networking and AIDS in Sub-Saharan Africa: Behavioural Research and the Social Context. Health Transition Series No. 4. Canberra: Australian National University.

Oucho, J.O. and W.T.S. Gould. 1993. "Internal Migration, Urbanization, and Population Distribution," in National Research Council, Demographic Change in sub-Saharan Africa. K.A. Foote, K.H. Hill, and L.G. Martin, eds. Washington, D.C.: National Academy Press. 256-296.

Packard, R.M. and P. Epstein. 1992. "Medical Research on AIDS in Africa: A Historical Perspective," in AIDS: The Making of a Chronic Disease. E. Fee and D.M. Fox, eds. Berkeley, CA: University of California Press. 346-375.

Peil, M. 1985. "Changing Structures: A Democratic Comparison," Contemporary Urban Research 10(2): 76-91.

Petersen, W. 1958. "A General Typology of Migration," American Sociological Review 23(3): 256-265. 
Piot, P. et al. 1987. "Retrospective Seroepidemiology of AIDS Virus Infection in Nairobi Populations," Journal of Infectious Diseases 155: 1108-1112.

Prothero, M. 1977. "Disease and Mobility: A Neglected Factor in Epidemiology," International Journal of Epidemiology 6(3): 259-267.

Quinn, T.C. 1994. "Population Migration and the Spread of Types 1 and 2 Human Immunodeficiency Viruses," in Proceedings of the National Academy of Sciences 91(7): 2407-2414.

Rodenberg, J. 1993. "Emancipation or Subordination? Consequences of Female Migration for Migrants and Their Families," in Internal Migration of Women in Developing Countries. New York: United Nations. 273-289.

Romero-Daza, N. 1994. "Multiple Sexual Partners, Migrant Labor, and the Makings for an Epidemic: Knowledge and Beliefs About AIDS Among Women in Highland Lesotho," Human Organization 53(2): 192-205.

Rosenzweig, M. and K. Wolpin. 1988. "Migration Selectivity and the Effects of Public Programs," Journal of Public Economics 37: 265-289.

Rutenberg, N., A.K. Blanc, and S. Kapika. 1994. "Sexual Behaviours, Social Change, and Family Planning Among Men and Women in Tanzania," Health Transition Review 4(Supplement): 173-196.

Sanders, D. and A. Sambo. 1991. "AIDS in Africa: The Implications of Economic Recession and Structural Adjustment," Health Policy and Planning 6(2): 157-165.

Serwadda, D. et al. 1992. "HIV Risk Factors in Three Geographic Strata of Rural Rakai District, Uganda,” AIDS 6: 983-989.

Sewankambo, N.K. et al. 1994. "Demographic Impact of HIV Infection in Rural Rakai District, Uganda: Results of a Population-Based Cohort Study," AIDS 8(1): 1707-1713. 
Summers, L.H. 1994. Investing in All the People: Educating Women in Developing Countries. EDI Seminar Paper No. 45. Washington, D.C.: The World Bank.

Thadani, V.N. 1982. "Social Relations and Geographic Mobility: Male and Female Migration in Kenya." Center for Policy Studies Working Paper No. 85. New York: Population Council.

United Nations. 1994. AIDS and the Demography of Africa. New York: United Nations.

— 1995. World Urbanization Prospects: The 1994 Revision. New York: United Nations.

United Nations Educational, Scientific, and Cultural Organization (UNESCO). 1994. Statistical Yearbook 1994. Paris: UNESCO.

US Bureau of the Census. 1995. HIV/AIDS in Africa. Health Studies Branch, International Programs Center, Population Division. Research Note Number 20.

Wilson, D., M. Armstrong, and S. Lavelle. 1991. "AIDS in Africa," AIDS Care 3(4): 385-390. 


\title{
POLICY RESEARCH DIVISION WORKING PAPERS
}

\author{
Recent Back Issues
}

1996

*83 Sajeda Amin, Ian Diamond, and Fiona Steele, "Contraception and religious practice in Bangladesh."

84 John B. Casterline, Aurora E. Perez, and Ann E. Biddlecom, "Factors underlying unmet need for family planning in the Philippines."

85 Geoffrey McNicoll, "Governance of fertility transition: Regularity and duress."

*86 John Bongaarts, "Population pressure and the food supply system in the developing world."

87 Sajeda Amin, "Family structure and change in rural Bangladesh."

*88 John Bongaarts and Susan Cotts Watkins, "Social interactions and contemporary fertility transitions."
*89 Cynthia B. Lloyd and Mark R. Montgomery, "The consequences of unintended fertility for investments in children: Conceptual and methodological issues."

* 90 Zeba Sathar and Sonalde Desai, "Work patterns in rural Pakistan: Intersections between gender, family, and class."

*91 Mark R. Montgomery, "Learning and lags in mortality perceptions."

92 Ann E. Biddlecom, John B. Casterline, and Aurora E. Perez, "Men's and women's views of contraception."
93 James F. Phillips, Fred N. Binka, Martin Adjuik, Alex Nazzar, and Kubaze Frank Adazu, "The determinants of contraceptive innovation: A case-control study of family planning acceptance in a traditional African society."
94 John Bongaarts and Sajeda Amin, "Prospects for fertility decline and implications for population growth in South Asia."

95 Barbara S. Mensch and Cynthia B. Lloyd, "Gender differences in the

* No longer available 
schooling experiences of adolescents in low-income countries: The case of Kenya."

96 Martin Brockerhoff and Ellen Brennan, "The poverty of cities in the developing world."

97 Carol E. Kaufman, "Reproductive control in South Africa."

98 John Bongaarts, "Trends in unwanted childbearing in the developing world."

99 Mary Arends-Kuenning, "How do family planning workers' visits affect women's contraceptive behavior in Bangladesh?"

100 Mark R. Montgomery and Cynthia B. Lloyd, "Excess fertility, unintended births, and children's schooling."
101 Mary Arends-Kuenning, "The equity and efficiency of doorstep delivery of contraceptives in Bangladesh."

102 Sajeda Amin, Ian Diamond, Ruchira T. Naved, and Margaret Newby, "Transition to adulthood of female factory workers: Some evidence from Bangladesh."

*103 Margaret E. Greene and Ann E. Biddlecom, "Absent and problematic men: Demographic accounts of male reproductive roles."

104 Michael P. Todaro, "Urbanization, unemployment, and migration in Africa: Theory and policy."

105 Geoffrey McNicoll, "Population and poverty: A review and restatement."
106 Sajeda Amin and Gilda Sedgh, "Incentive schemes for school attendance in rural Bangladesh."

107 Martin Brockerhoff and Paul Hewett, "Ethnicity and child mortality in subSaharan Africa."

108 Ann E. Biddlecom and Bolaji M. Fapohunda, "Covert contraceptive use: Prevalence, motivations, and consequences."

109 John Bongaarts and Griffith Feeney, "On the quantum and tempo of fertility."
110 Barbara S. Mensch, Daniel Bagah, Wesley H. Clark, and Fred Binka, "The changing social environment for adolescents in the Kassena-Nankana District of northern Ghana: Implications for reproductive behavior."

111 Martin Brockerhoff and Ann Biddlecom, "Migration, sexual behavior, and HIV diffusion in Kenya." 